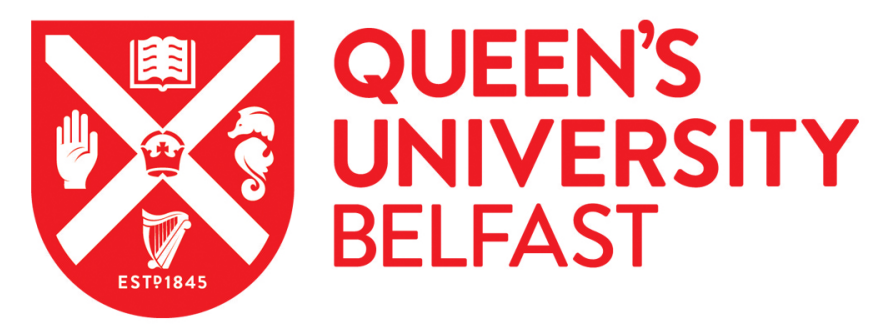

\title{
Teacher Development through Coteaching Outdoor Science and Environmental Education Across the Elementary-Middle School Transition
}

Kerr, K. (2019). Teacher Development through Coteaching Outdoor Science and Environmental Education Across the Elementary-Middle School Transition. The Journal of Environmental Education. https://doi.org/10.1080/00958964.2019.1604482

Published in:

The Journal of Environmental Education

Document Version:

Peer reviewed version

Queen's University Belfast - Research Portal:

Link to publication record in Queen's University Belfast Research Portal

\section{Publisher rights}

Copyright 2019, Taylor \& Francis.

This work is made available online in accordance with the publisher's policies. Please refer to any applicable terms of use of the publisher.

\section{General rights}

Copyright for the publications made accessible via the Queen's University Belfast Research Portal is retained by the author(s) and / or other copyright owners and it is a condition of accessing these publications that users recognise and abide by the legal requirements associated with these rights.

Take down policy

The Research Portal is Queen's institutional repository that provides access to Queen's research output. Every effort has been made to ensure that content in the Research Portal does not infringe any person's rights, or applicable UK laws. If you discover content in the Research Portal that you believe breaches copyright or violates any law, please contact openaccess@qub.ac.uk. 


\title{
Teacher Development through Coteaching Outdoor Science and Environmental Education Across the Elementary-Middle School Transition
}

\begin{abstract}
This study considers the benefits of coteaching in the context of the outdoors. It explores the use of coteaching in a professional development programme and investigates all the cited outcome categories for teachers: cognitive, affective, coteaching and professional development. Coteaching pairs co-planned, cotaught and co-evaluated 'Shared Learning Days' in the outdoors. Eight teachers took part with 180 students in their last year of elementary school or their first year of (junior) high school. This paper demonstrates how a model of professional development, with coteaching at its core, is beneficial for the development of teachers who are teaching 'outside' their comfort zone (outdoors) and expected to focus on skills-based teaching and learning. In particular, the benefits of attitudinal change among the teachers involved is discussed.
\end{abstract}

Keywords: professional development; elementary/primary school; secondary/high school; outdoor learning

\section{Background}

\section{Learning outdoors - teacher confidence and skills-based approaches}

Outdoor learning is not without its challenges for teachers, schools and students. Research in the area of outdoor learning has also identified real and potential issues for schools, teachers and students. Dillon, Rickinson, Teamey, Morris, Young Choi, Sanders and Benefield (2006) reported on the key findings from a critical review of 150 pieces of research on outdoor learning and site issues such as prior knowledge and experience, fears and phobias, health and safety issues, learning styles and preferences (Dillon et al., 2006). The issue of teacher confidence in relation to teaching outside is well-documented (Dillon and Dickie, 2012) and was one of the most prevalent challenges reported in the implementation of outdoor learning in the Natural Connections project (Waite, Passy, Gilchrist, Hunt \& Blackwell, 2016)..

In addition to issues surrounding teacher confidence in the outdoors, teachers also report a lack of confidence in teaching and learning science/environmental education. This is 
particularly cited for non-science specialist elementary teachers (Addis et al., 2007, ETI, 2015). In their insight study for the Natural Connection project, Rickinson, Hunt, Rogers and Dillon (2012) reported that teachers referred to a lack of confidence as one of the main constraints for outdoor learning. Nundy, Dillon and Dowd (2009) also cite teacher confidence as one of the main influencing factors for effective outdoor learning. They relate teacher confidence to Bandura's Perceived Self-Efficacy which asserts that people's beliefs about themselves will affect their performance (Bandura, 1994; Nundy et al., 2009). In other words if teachers do not feel confident and do not believe they can teach well outdoors, then the outdoor learning and teaching will not be effective.

In the UK there has been a shift towards a greater focus on skills-based teaching and learning, particularly at elementary level. Such curriculum changes in relation to a skills focus are not unique to the UK. The development of the Next Generation Science Standards in the United States, for example, also demonstrates a move towards a focus on inquiry and skills integrated across disciplines (University of Southern California, 2013). A focus on skills-based teaching and learning brings fresh challenges for many teachers, particularly when teaching outside their comfort zone - in the outdoors.

\section{The context for the study - Northern Ireland}

An "explicit emphasis on the development of skills" is at the heart of the Northern Ireland curriculum for the purposes of lifelong learning and "operating effectively in society" (CCEA, 2007, p. 5). In particular, the Northern Ireland curriculum states that students should progressively develop cross-curricular skills (Commination, Using Mathematics, Using Information and Communications Technology). They should also develop Thinking Skills and Personal Capabilities (Thinking, Problem-Solving and Decision-Making, Self-Management, Working with Others, Managing Information, Being Creative) (CCEA, 2007). 
This focus on skills based development is emphasised as a major benefit of outdoor learning. In Northern Ireland, one of the underlying purposes of the revision in the curriculum was to give teachers the flexibility to modify the curriculum in order to remove barriers to learning and meet the needs of all learners. Specifically, it is recommended that teachers modify tasks or the environment for learners. Modifications in the environment is emphasised at elementary level in order to "best meet the needs" of students (CCEA, 2007, p.14). Autonomy and flexibility to change the curriculum was made possible by a decrease in prescribed content and a greater focus on skills development. It can be argued that greater autonomy and a decrease in prescribed knowledge-based content allows for a greater emphasis on progressive skills development. However, the impact of such curriculum change cannot be understated. For example, a case study of Northern Ireland's curriculum review reported that teachers were frustrated by being "forced to respond to too much change too quickly" (Gallagher, 2009, p.1).

Curriculum revision in Northern Ireland was seen by many as overwhelming in relation to autonomy, flexibility and a skills-based focus. In addition, there were also changes to how science is taught. Previously science was taught as a subject on its own but now it has to be taught with history and geography as part of 'The World Around Us' (WAU) learning area. There is ongoing concern that teachers' lack of confidence in science has led to their ignoring science and concentrating on teaching only history and geography (Addis, Reid, McAlister and Shine, 2007). This has resulted in a call for ongoing professional development in the area to meet the challenges of delivering all three subjects (science, history and geography) in a combined way.

Whilst the revision in the curriculum in Northern Ireland happened some 10 years ago, the impact on the teaching of science has been far reaching and is still frequently cited. An evaluation by the Northern Ireland Education and Training Inspectorate in 2014 emphasised this ongoing concern with only $54 \%$ of responding schools stating that they include "the 
progression of relevant practical and experiential (science and technology) skills within their WAU planning" (ETI, 2015, p. 1). Lack of access to training is cited as one of the main reasons for this issue with recommendations to help primary schools by "including expertise from the post primary sector" and the dissemination of good practice to include transition projects between elementary (primary) and (junior) high schools (post primary).

In relation to outdoor learning, Rickinson et al. (2012, p.16) report that teachers also talked about a lack of "expertise and inspiration from others" and how important this is. Nundy et al. (2009, p.63) discuss two key elements for improving self-efficacy and confidence to teach outdoors - "opportunities to see other people manage tasks successfully" and "peer persuasion". They suggest several important elements to improve teacher confidence and preparation for teaching outdoors - namely, training and support, collaboration and "team teaching" (Nundy et al., 2009; Hanna, 1992). The professional development programme presented in this paper combined all of these elements and focused on the sharing of good practice across the elementary and (junior) high school transition phase, as specifically recommended in the Northern Ireland context (ETI, 2015). However, coteaching was used as opposed to team teaching.

\section{The professional development programme - Coteaching, training and in-class support}

Coteaching differs from team teaching in that it requires teachers to work together to actively participate and take responsibility for all stages of planning, teaching, assessing and evaluating. Teachers work together within a specified unit of work or lesson, whereby they learn from one another by teaching at the elbow of another (Martin, 2009; Tobin and Roth, 2006). Murphy, Bianchi, McCullagh and Kerr (2013) state that coteaching provides teachers with a structure to reflect on theory, praxis and practice. The need to co-plan prevents teachers feeling isolated which "typically results in maintaining current teaching practices, rather than changing lessons to meet students' differing needs" (Murphy et al., 2013, p.176), which was 
cited as a reason for the revision of the Northern Ireland curriculum. In addition, coteaching has been shown to improve the quality of teaching, which resulted in an increase in student academic achievement, greater enjoyment of science and the development of positive and sustainable teaching approaches for pre-service and in-service teachers (Martin, 2009).

Similar to the approach implemented in the projects outlined by Murphy et al. (2013), this professional development programme employed a coteaching methodology. Elementary and (junior) high school teachers 'learnt together' by their co-participation in specifically designed professional development courses for teaching in the outdoors. After which they 'taught together' to put into practice what they had learned on the courses by co-planning, coteaching and co-reflecting (Murphy and Beggs, 2010). As with previous coteaching projects outlined by Murphy et al. (2013), the curriculum content and approaches to teaching outdoors with a skills focus were new and challenging for the majority of teachers involved. Teaching science in the outdoors was particularly challenging for the elementary teachers, who were not specialists in teaching science/environmental education and did not hold undergraduate science/environmental degrees.

During the workshops, teachers were briefed about the theoretical underpinning of coteaching and how it can look in reality. They also designed and signed a code of conduct and worked through different scenarios that have arisen in previous projects and then worked together to suggest solutions (for example, teacher absence, lack of commitment by one/two of the coteachers, changes to school timetables). This process was informed by best practice and lessons learned through the wealth of previous coteaching studies (Kerr, 2010; Murphy and Beggs, 2010; Murphy and Scantlebury, 2010).

The coteaching model was used to afford the elementary and (junior) high school coteaching teams the opportunity to learn from each other and was designed to address some of the specific issues they faced, as discussed in the first section of this paper: 
- the expectation of a greater focus on skills-based approaches (CCEA, 2007; Gallagher, 2009)

- confidence in teaching and learning science/environmental education (particularly for non-science specialist elementary teachers) (Addis et al., 2007, ETI, 2015)

- confidence in teaching and learning in the outdoors (Dillon and Dickie, 2012; Waite et al., 2016)

This model of working together can be represented in an adaptation of Murphy and Beggs' (2010) original model of coteaching (Figure 1). Instead of the mutual development of a student teacher and classroom teacher (Murphy and Beggs, 2010, p.12) this adapted model of coteaching shows the mutual development of an elementary expert (Teacher 1) and a (junior) high school science expert (Teacher 2). In the context of the current study, the premise of the model is that each will bring their expertise in science/environmental education, curriculum and pedagogical knowledge from their respective education levels. This is for the mutual benefit of the other teacher as well as for the students. 


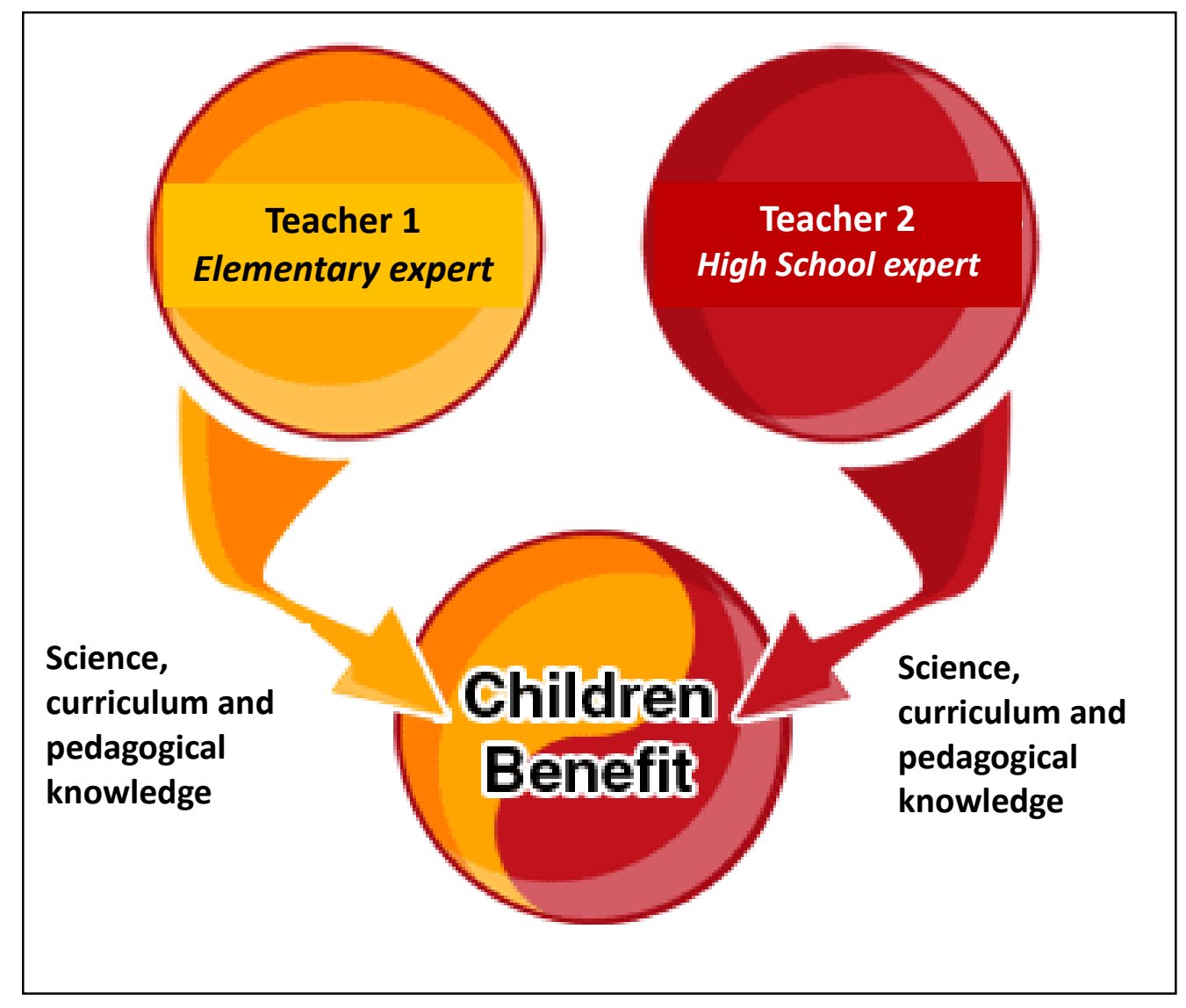

Figure 1. An adaptation of Murphy and Begg's (2010) coteaching model for an elementary/ (junior) high school teaching team. 'Children' are referred to as 'students' in the current study.

A coteaching (co-planning and co-evaluation) model will only work when both teachers (and their classes) are committed to, and working on, the same learning and teaching experiences/lessons/schemes of work. Coteachers worked closely together from the outset, that is, during the initial professional development workshops. Coteachers worked in their pairs during these workshops - one elementary teacher and a (junior) high school teacher from a neighbouring high school.

The effectiveness of professional development and training programmes in general, and more specifically for science/environmental education, are frequently critiqued. Issues referenced include their sustainability and the likelihood of long term changes to teaching and learning practices beyond the professional development 'course' or workshop (Rodrigues, 
Marks and Steel, 2003; Kerr, 2010). Following a review of professional development programmes, a checklist of core criteria for effective professional development is presented by Kerr (2010). These are "active participation, focusing on the needs of specific teachers and pupils [student], working together, reflection, presentation of work and a long term/on-going element" (Kerr, 2010, p.155). The professional programme presented in this paper included all of these core criteria through the integration of the coteaching model outlined in Figure 1. The coteachers learned together in the workshops before they co-planned and cotaught (Kerr, 2010). The current study implemented and adapted this best practice but with an outdoor learning focus.

The integration of a professional development programme with in-class support and a very well established model of coteaching for elementary and (junior) high school coteachers has resulted in an extension to the aforementioned coteaching model (Murphy and Beggs, 2010). Figure 2 presents this extension with the inclusion of professional development workshops and in-class support as a backdrop. There is also recognition within the model that both the elementary and (junior) high school teachers mutually benefit from this approach to professional development. 


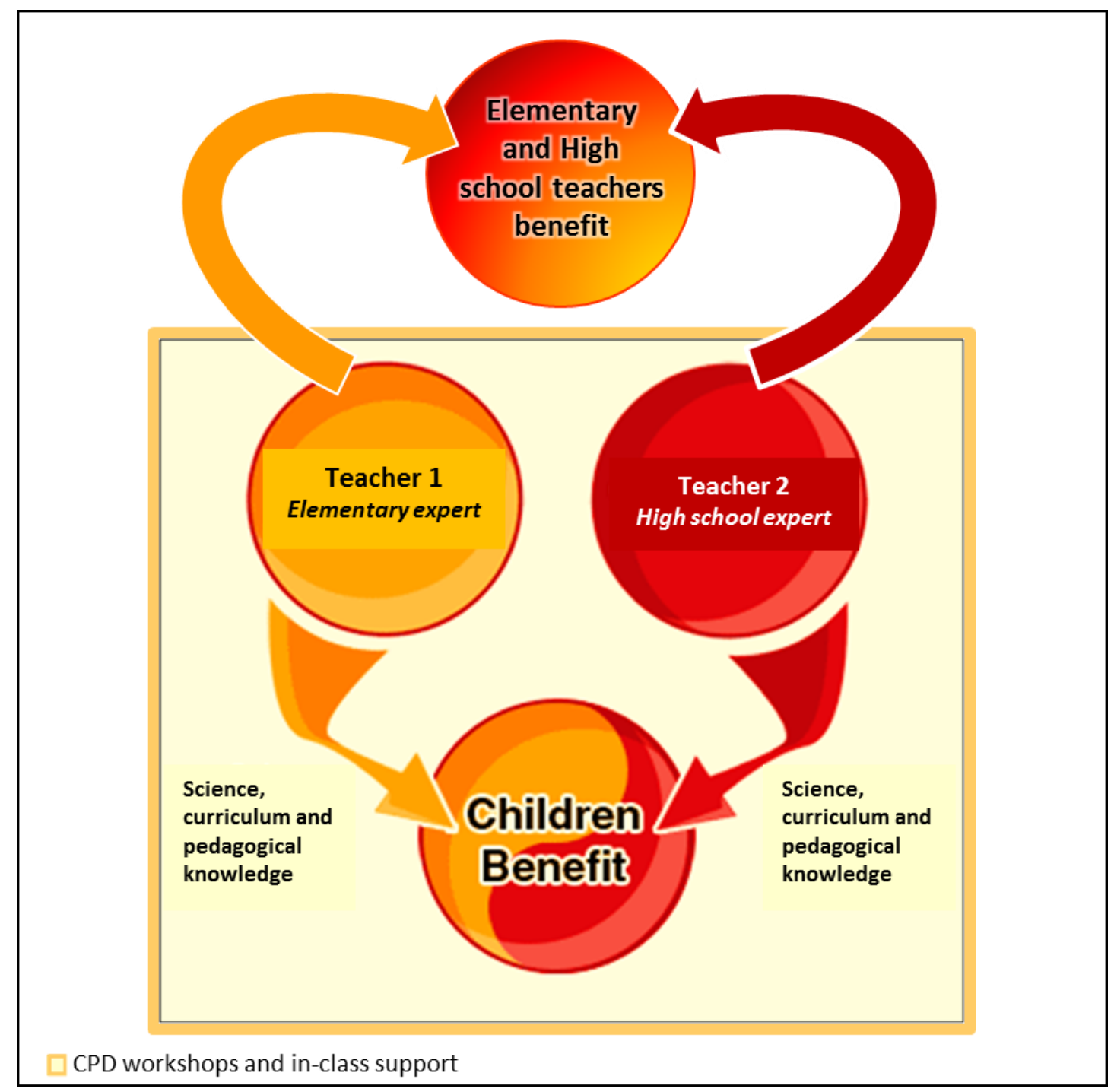

Figure 2. A blended CPD model for coteaching and learning science in the outdoors (built on the original model by Murphy and Beggs, 2010). 'Children' are referred to as 'students' in the current study.

In-class support and collaboration is often cited as a core element for sustainable changes to teaching practices through professional development (Kerr, 2010; Nundy et al., 2009; Rickinson, 2012). The coteachers supported each other during the coplanning and coteaching of shared learning (and teaching) days in the outdoors. The shared learning (and teaching) days were built into the remit of the project to deliver the coteaching model and to enhance its effectiveness. Teachers were asked to co-plan these days and both classes of students were to embark on the learning experiences together. 
Various activities were designed by the teachers to best meet the needs of their students and included a range of studies from an exploration of ancient trees to a comparison of bugs found on school grounds at different times in the year. The outdoor spaces varied as the teachers worked together to decide the best venues. They took into account the needs of their students and what they felt comfortable with. All locations were either in school grounds (two coteaching teams) or in local parks (the other two coteaching teams). However, it is important to note that whilst the locations were local, the elementary teachers acknowledged that they had not used the outdoors to teach before. However, the (junior) high school teachers were science specialists and had conducted fieldwork in this way, although not with children so young. This further strengthened the pedagogical learning potential between the coteaching teams. Working together in this way was particularly beneficial for the elementary teachers who would be teaching in the outdoors (outside their comfort zone) but with the help of experienced (junior) high school teachers.

Interestingly, the lessons based on school grounds took place on the (junior) high school sites as these sites offered greater opportunities - one team used the school pond on their site and the other used a wooded area. The other two coteaching teams visited local parks. One pair availed of a pond and wood within a country park and the other, some ancient trees within a local public park. Rickinson et al. (2004) highlighted the importance of 'place' for student outcomes when planning outdoor teaching and learning - the coteaching teams were very aware of this and ensured that they choose spaces which were comfortable for all involved. The spaces chosen also mapped on to the teachers' workshops as they utilised some of the resources and ideas they had become familiar and comfortable with during these sessions. 
The roll out of this model and its components was qualitatively evaluated from the teachers' perspective. The programme was also evaluated from the students' perspective and is reported elsewhere (Kerr, 2016).

\section{Methods}

The programme was evaluated using carefully designed in-depth interviews, reflective diaries (completed before, during and after the project) and video and photographic records during activities. This study examined the outcomes of a professional development model of co-planning, coteaching and co-evaluation through shared learning and teaching days in the outdoors across the elementary, (junior) high school transition phase. The interview structure for the teachers was related to outdoor learning (enjoyment, usefulness), the use of this model to address transition between elementary and (junior) high school, their thoughts on how the coteaching element of the model worked/did not work, usefulness of the workshops and professional development, whether or not the lessons will be continued/repeated as well as how they would improve the programme if they were to run it again. The reflective diaries were written reflections on each element of the programme and how useful (or not) they were - from the initial introductory workshop, through the co-planning, coteaching of the shared learning days until the final celebration event to present the work with the students. The reflective diary was piloted many times in other coteaching projects involving the author and experts in the area of coteaching (Murphy and Beggs, 2010).

A detailed student questionnaire was conducted online before and after the study and focus groups were conducted face to face with students. Whilst the findings from the students are beyond the remit of the current paper, these measures evidenced very positive results and are reported elsewhere (Kerr, 2016). 
The findings presented here are from the teacher evaluation in relation to the impact of this model of professional development. The qualitative evaluation set out to address the following research questions:

1. How beneficial was the model of teacher professional development for helping the teachers in dealing with a skills- based focus for teaching and learning?

2. How beneficial was the model of teacher professional development for helping teachers to teach in the outdoors?

\section{The participants}

Teachers from four elementary and four (junior) high schools in Northern Ireland took part. For the most part, there is no distinction between middle/junior high school and high school in Northern Ireland. Children in these education phases are all in the same schools and are taught by the same teachers. This is important to note as the (junior) high school teachers teach students up to the age of 18 years old, to include those preparing for university entrance level examinations. In other words, they are highly specialist in their science area(s). All eight teachers were involved with students in the transition years. Four of these teachers taught students in their final year of elementary school (10-11 years old) and four of them were science teachers for the students in their first year of (junior) high school (11-12 years old).

\section{Data analysis - analysing and reporting the outcomes of outdoor learning}

Rickinson, Dillon, Teamey, Morris, Young Choi, Sanders and Benefield (2004, p.17) outlined the trends within research on outdoor learning over the two decades prior to their publication which have culminated in the surfacing of more critical explorations of "the conceptual and theoretical aspects". The journey of research in the area of outdoor learning generally aligns to the development of social science research more broadly - from quantitative pre-post and post-test designs to look at the impact of outdoor interventions in the early 1990s 
to meta-analyses calling for a more in-depth look at the processes of outdoor learning in the mid-1990s. This development in research has resulted in more qualitative and mixed-methods studies at the turn of the decade (Rickinson et al., 2004). In more recent reviews of environmental and outdoor education, the trend towards post-qualitative, often mixed methods approaches is still evident. In their systematic literature review of environmental education programmes, Stern, Powell and Hill (2014) included 86 studies 1999 and 2010 - of these, 54 employed qualitative methods and 35 were mixed methods studies. Ardoin, Bowers, Wyman Roth, and Holthuis (2018) systematically analysed 119 empirical studies that measured outcomes between 1994 and 2013, and almost a third of those incorporated qualitative approaches. The current study embraced the best practice in research design in the area of outdoor learning over the past two decades by engaging in a critical exploration of the conceptual and theoretical aspects of outdoor learning through the use of a qualitative approach.

When considering the impact and possible effects/benefits of outdoor learning, leading researchers in the area have presented several conceptual and theoretical underpinnings. Rickinson et al.'s (2004) earlier categorisation of the impacts outlined in the literature were: cognitive impacts (knowledge and understanding), affective impacts (attitudes, values, beliefs and self-perceptions), interpersonal/social impacts (communication skills, leadership and teamwork) and physical/behavioural impacts (physical fitness, physical skills, personal behaviours and social actions). Stern et al. (2014) acknowledge that their work led on from Rickinson's as they included similar outcome categories in their literature review: knowledge, awareness, skills, attitudes, intentions, behaviour and enjoyment. Ardoin et al. (2018) critique these more traditional categorisations as they tend to be focused only on knowledge, attitudes, skills and behaviour. They present their review as including a more nuanced exploration of outcomes beyond those traditionally considered in environmental education. Ardoin et al. (2018) identified six broad categories: knowledge, dispositions, competencies, behaviour, 
personal characteristics and multi-domain outcomes (for example, academic outcomes which can be knowledge based and related to competencies). Rickinson et al. (2004) acknowledged a considerable degree of overlap between their categories and Ardoin et al. (2018) recognised the same issue through the inclusion of a multi-domain categorisation. More specific to early years' and elementary phases, Waite (2013) summarised the theoretical perspectives and contributions of learning outside the classroom as having a psychological plane of focus (personal, intrapersonal and psychosocial contributions) and a socio-cultural plane of focus (interpersonal societal contributions). Whilst more nuanced categorisations are useful for the purposes of review and acknowledging the degree of overlap, the four broad categories of cognitive, affective, interpersonal/social and physical/behavioural outcomes are the most succinct as a starting point for data analysis. This is because they do not involve a long list of possible contributions/effects of outdoor learning and most outcomes cited can be mapped on to them initially.

Also, it is recognised that these categorisations are mainly used to describe the benefits of outdoor learning for students/participants and less so for teachers. However, it transpired during the iterative process of data analysis that the majority of teacher's comments also aligned broadly with some of these categories (cognitive and affective), but less so with others (interpersonal/social and physical/behavioural). An iterative process of reanalysis in line with the literature related to teacher development and outdoor learning was conducted. This gave rise to additional teacher-specific categories unique to their development and those specific to working as coteaching teams:

- Cognitive - curriculum and subject content knowledge, teaching practice and environmental knowledge. Teaching practice was also categorised as one of the four main benefits for teachers in the Natural Connections Project (2016) and was reported as the most positive impact. Perhaps unique to the professional development 
programme reported in the current study was the sharing of knowledge of subject content across the transitions stages. This was something the teachers talked about at length in their interviews.

- Affective - empowerment, confidence and enjoyment. Confidence and enjoyment were also reported as benefits in the Natural Connections project (Waite et al., 2016). Waite (2011) also found that 'fun' was a specific personal value related to outdoor learning for practitioners. Stern et al. (2014) also include 'enjoyment' as an outcome category.

- Coteaching - autonomy and sharing. Autonomy was also reported by Waite (2011) with reference to teaching outdoors.

- Professional development - teaching practice, confidence, sustainable change. Professional development was also reported as a positive impact in the Natural Connections project (Waite et al., 2016).

Data from the teacher interviews and reflective diaries were themed and categorised in line with the four categories of outcomes/impacts outlined: cognitive, affective, coteaching and professional development. An iterative process was carried out similar to the process of qualitative verbal data analysis outlined by Chi (1997). It is important to note that the process of developing themes resulted in constructs taken from the teachers ideas, perceptions and reflections and cannot be generalised as more than that. The data collected were 'slices of social life' that 'portray moments in time' and the research tool used meant that the subjects had the opportunity to express everyday understandings in a social context (Charmaz, 2000).

\section{Findings}

The findings are presented in line with the outcome categories identified (cognitive, affective, coteaching, professional development) and in relation to the issues with delivery of outdoor learning in a Northern Ireland context. 


\section{Cognitive outcomes - curriculum and subject content knowledge, teaching practice and environmental knowledge}

For the teachers, knowledge and understanding of several aspects was developed through their participation in the programme: the level and content of science/environmental education covered in the coteacher's Key Stage (curriculum content), their own subject knowledge and skills as well as knowledge of how to conduct outdoor learning activities and use the appropriate resources (teaching practice).

Dealing with a skills based focus.

In their post-programme interviews, the teachers talked about how their involvement in the project raised their awareness of the level and content of science/environmental education in the elementary school and/or (junior) high school curriculum. However, the teachers commented that doing a project like this is a way of bridging the transition gap and raising awareness and knowledge of what is covered in the other stage and how to prepare lessons accordingly:

Getting a better understanding of what they will be doing in science in year 8 and the concerns of the girls knowing much less but more about what I can do here. We are tied by our statutory requirements but I can look at what I can do here.

$$
\text { ([junior] high school teacher) }
$$

I now have more of an idea of how to structure those types of lessons and the content, making sure it's age appropriate because things like food chains and food webs.

(elementary teacher)

The teachers also commented on how much the CPD activities made them think and developed their skills in using the equipment:

I thought the thing in Botanic [Gardens] was refreshing because I don't think there has been a lot of science teaching promoted for outdoors and a refreshment of the different activities and the fun activities you could do with the pupils was very good and running 
through how to use clinometers...it was out and about and it gets you thinking again.

([junior] high school teacher)

\section{Teaching sciencelenvironmental education and teaching in the outdoors.}

In relation to changes in their own teaching and learning practices, teachers talked about an increase in their subject knowledge as well as their confidence to teach the material:

The post-primary [(junior) high school] teacher developed the programme and my role was to do the presentation but that would definitely shift next year because I am more confident with being able to deliver it, I have a better understanding and I learnt a lot, I learned a lot from her... I would be confident to do this myself now... why have I not done this already? Because I was less comfortable with science, history and geography takes over! (elementary teacher) We can borrow their equipment and aware of what you need for a lesson like that

(elementary teacher)

You have it all there and it's another topic you've learnt yourself that I wouldn't have had a clue about before. So it was actually beneficial in that way because you're actually learning new stuff yourself as well as passing it on to the children

(elementary teacher)

Every coteaching pair developed classroom resources to deliver the content as well as work booklets for the students. Perhaps the most fascinating element of this work was the very different concepts and learning intentions chosen by each pair of teachers, a reflection of increased knowledge and understanding of the material and how to develop resources for teaching and learning in the outdoors. In their interviews, every teacher stated that they achieved the aim of developing successful classroom materials to support their teaching in the outdoors:

Definitely achieved this aim - the base is there and we can add to it - I now have more of an idea of how to structure those types of lessons and the content. 
There was also an emphasis on environment-related knowledge and awareness of caring for the environment. Half of the teachers involved planned and implemented sessions which focused on caring for species within the environment and river conservation (to include a visit to a local rivers agency). Teachers talked about the development of their own learning with regard to the environment:

The topic we chose, we did the woodlands and the ancient trees to start with. I had to teach myself the topic before I did it with the children, that's being honest, a lot of the stuff about trees and measuring trees and how to recognise ancient trees and about the environment and about ecosystems and that, I didn't necessarily know off hand and I had to go and spend time researching that and sat with (my partner) teacher and went out looking and got resource booklets and printed stuff off with the other teacher from the other school.

(elementary teacher)

\section{Affective outcomes - empowerment, confidence and enjoyment}

The development of teacher's affective outcomes included empowerment and confidence to teach science/environmental education in the outdoors - their enthusiasm and enjoyment for teaching in this way was also evident.

\section{Dealing with a skills-based focus.}

In relation to affective outcomes, the teachers talked about feeling empowered and having the confidence to dealing with the issue of building science skills into their teaching within the Curriculum:

Now that I have all this knowledge, I need to be building my science in weekly, more structured, so that is what this has empowered me to do...I can work with the high school... how can we enhance the academia a bit more? I'm sitting with a good group of kids with good knowledge. 
Teaching sciencelenvironmental education and teaching in the outdoors.

All of the teachers involved explicitly commented on how much they enjoyed the project and how novel it was:

I think it was really positive, I really enjoyed myself.

$$
\text { ([junior] high school teacher) }
$$

I enjoyed every minute of it. It's great, it has just been great.

$$
\text { (elementary school teacher) }
$$

This enthusiasm led to real and sustainable changes to learning and teaching in the outdoors within their schools and departments. As well as their own enjoyment, the teachers also talked about how obvious the enthusiasm and enjoyment was amongst the students:

Seeing the pupils, their enthusiasm, how they loved being outside, the pond, looking at creatures, it was amazing. I've never seen them so engaged and enthusiastic about something...it was really, really positive.

$$
\text { ([junior] high school teacher) }
$$

\section{Coteaching - autonomy and sharing}

The teachers focused on their development as a result of working and teaching together (coteaching) which led to them being more autonomous when teaching science/environmental education in the outdoors. Their relationships and communication with their coteachers was also of great benefit for the purposes of sharing ideas. These relationships also helped build transition links between schools and teachers as they teach students who have just transitioned between schools (junior high school students) or who are about to transition (elementary students).

Dealing with a skills-based focus. 
When talking about meeting the other teachers and working together in coteaching teams, several people talked about how this led to embracing the development of children's skills beyond their main subject work. In particular, they talked about subsequent years and focused on how they could autonomously integrate teaching in the outdoors when they returned to their regular teaching:

The primary [elementary] teacher was really out of her comfort zone because she's from an English/drama background but said she would do this again next year and be able to do it on her own as well.

$$
\text { ([junior] high school teacher) }
$$

I feel I could use this again because I know I have the resource now for the topic, I have all the background, we made Power Points, we found out about it ourselves. So if I was to do this again with another year group, you have it all there and it's another topic you've learnt yourself that I wouldn't have had a clue about before.

$$
\text { ([junior] high school teacher) }
$$

\section{Teaching sciencelenvironmental education and teaching in the outdoors.}

Teachers talked about being able to share ideas as a result of co-planning and coteaching and how their relationships and communication grew as a result. In particular, various teachers commented on making use of the science/environmental expertise of the (junior) high school teacher:

It was good because when you do have doubts you're reassured by the other person or they're giving you ideas, it's just the sharing.

(elementary teacher)

It worked out well, she knew what she was at...for the outdoor science, whenever we were out, she was able to come up with ideas...we were both there so for the morning and the afternoon we could switch activities. Having the expertise there because she was science. 
A running theme throughout the interviews was the shared learning from working together with a coteacher and the other teachers involved:

Meeting people from other schools and finding out what they are doing with World Around Us and how much science they are doing or not doing.

(elementary teacher)

\section{Professional development - teaching practice, confidence, sustainable change}

Long term and sustainable change to the practice of teaching in the outdoors was evidenced by all the coteachers and schools involved to include whole school planning changes and the support at leadership level. All of the schools involved continued the work with new students in subsequent years.

Dealing with a skills-based focus.

In relation to having the confidence to teach in this way because of what they learned, the teachers talked about the specific activities carried out during their CPD workshop days, the skills they developed and how much of it they used to plan their resources and teaching:

The initial workshop with the Field Studies Council - getting you physically involved in doing something rather than just being told about it, you're actually doing it yourself you get much more out of it, it's more meaningful and you can see how it's going to work with the children...we did a lot of those games then in our project... what stood out for me was when we actually went outside and did it yourself.

(elementary teacher)

Our P7 (last year of elementary school) teacher now has all those skills, all those resources saved physically in her classroom and she will now take that forward because she said herself that, doing the World Around Us, it has opened that up for her.

(elementary teacher) 
The teachers talked about long term and sustainable positive change to the practice of teaching science/environmental education in the outdoors in relation to three themes: changes to their own teaching and learning practices, changes to the general science curriculum in school and the development of the outdoor science/learning throughout their schools.

At the minute the school is drawing up a new 'World Around Us' policy and scheme which is only starting to be created now so stuff like that will go in to the new scheme for the older children... when they were doing the questionnaire, they were saying but we don't do science, they were very aware that they're not doing it.

(elementary teacher)

We are trying to develop a better programme of study so that they are more prepared for year 8 and it isn't as much of a jump.

(elementary teacher)

The majority of teachers also talked about developing outdoor science within their schools and departments as a result of the programme:

I'm glad it's [outdoor learning] brought it to the forefront and I have said to the other feeder primary [elementary] schools that I do the science club with, we're going to do the fieldtrip too, we're going to bring them into school a day or two for one session practicals.

$$
\text { ([junior] high school teacher) }
$$

Teaching sciencelenvironmental education and teaching in the outdoors.

In particular, the teachers enjoyed meeting other teachers, sharing practice, having access to resources and equipment as well as 'up-fronting' outdoor learning as a vital part of and change to their teaching and learning practice:

It was good, it did make us think as science teachers too that this has gone to the wayside, the fieldtrips, and the fieldtrips were always good, you remember them yourself. I'm glad it's brought it to the forefront. 
Sustainable change was evidenced by the teachers' future plans. Every school indicated that they will take the project forward in its current format, develop the resources further or open it up to more schools and/or involve more students in the relevant year group:

We will continue it next year - will do it again - we will use this project as a base to take it further, now that I know the level to pitch it at and website and resources that I can go to, to get the stuff. We might revise it slightly to do it a bit earlier and leave a month's break or maybe go out of the school grounds and discuss this.

(elementary teacher)

As well as the development of teaching science and the curriculum outdoors, several teachers also talked about having the school leadership and management on board to take this work further:

The principal is pushing that forward, keen to go ahead with this, she's pushing it in school, got the materials for outdoors now so want to do it again now.

$$
\text { ([junior] high school teacher) }
$$

The principal, today, asked could we take that out (resource from one of the project workshops) to other schools and showcase it around other schools.

(elementary teacher)

\section{Discussion}

This paper set out to present the outcomes, for teachers, of a blended CPD programme model designed to address contemporary issues faced by educators in Northern Ireland and beyond with regard to: the expectation of a greater focus on skills-based approaches, confidence in teaching and learning science/environmental education (particularly for nonscience specialist elementary teachers) and confidence in teaching and learning in the outdoors. The project model was based upon work which has benefitted from a wealth of earlier successful CPD programmes (Kerr, 2010; Murphy and Beggs, 2010; Murphy and Scantlebury, 2010). The outcomes of the programme were evident across various domains as outlined in the 
literature: cognitive impacts, affective impacts, the impact of the coteaching model and professional development.

\section{Coteaching within a blended model -the impact when 'outside' a comfort zone}

The majority of teachers involved in this project had very little experience of outdoor learning. The findings from this study show that by co-planning, coteaching and co-evaluating the partner teachers developed cognitively, affectively, through working together using coteaching (development of autonomy and sharing) and professionally. Similar gains are reported in several coteaching studies from which the current model was adapted (Murphy and Beggs, 2010). However, findings in this paper demonstrate that the model works with inservice teachers, as opposed to pre-service teachers (student teachers), who are 'outside' their comfort zone and who are learning in a new and often daunting (Dillon et al., 2006) contextthe outdoors! Findings from previous coteaching studies reported positive change for the preservice and in-service teachers after the coteaching project, when they were 'solo' teaching. Effective classroom teaching and sustainable change at school level is also reported for inservice teachers and improved 'solo' teaching grades (as part of their initial teacher education course) for their partner pre-service teachers (Murphy and Beggs, 2010). The in-service teacher partners in the current study also reported a long term change to their teaching practice and changes to whole school plans and approaches, both for science/environmental education and outdoor learning.

Further research is needed to look in more detail and in more depth at the processes behind such empowerment and gains across all four impact categories through the use of this model. For example, more recently, Murphy, Scantlebury and Milne (2015, p.281) successfully proposed a "more nuanced developmental and learning explanatory framework" for the benefits of a coteaching model between per-service and in-service teachers - Vygotsky's zone of proximal development. 


\section{Coteaching leads to a social, recursive and reflexive shift in pedagogy}

The model of coteaching adopted in the current study involved co-planning and coevaluation as well as coteaching in the outdoors, whereby the teaching pairs learned by teaching at the elbow of another (Martin, 2009; Tobin and Roth, 2006). As Siry and Martin (2010, p.65) pointed out that this model of coteaching has the "underlying concept" that educators are "being in/with" each other. This gives each coteacher a "first-person perspective from which to analyse an individual's decisions" in relation to choice of curriculum, the order materials will be delivered in as well as the teaching strategies and assessment they will use Martin (2010, p.65). This underlying concept was evident in the coteaching related outcomes for the coteachers involved in the current programme as they talked about developing a relationship with their coteacher, learning from each other, professionally developing, sharing ideas and communicating throughout and beyond the programme. Many of these relationships continued to grow when the programme ended and led to other coteaching projects. Siry and Martin (2010, p.65) described this as an "epistemological shift" which happens as a result of such a recursive, reflective process. The coteachers in their study, as with the current study, could change their ideas about teaching as they change their ideas about learning by coteaching with others.

Increased autonomy in relation to teaching in the outdoors was also reported by the coteachers in this project. In her survey of personal values, alternative pedagogies and standards, Waite (2011) also reported that teachers benefitted by being more autonomous whilst teaching outdoors. However, Waite (2011) highlights this data came from childminders who may well be less constrained than organisations (such as schools) so it interesting to see the development of autonomy through the use of coteaching in the current study.

Roth (2007) reported that the coteaching experience was transformative and empowering for those involved as there is a focus on understanding praxis and contributing to 
decision making for a specific purpose. In the case of the current study such a transformation resulted in engagement with outdoor learning and coteaching for the first time - a huge leap for some of the coteachers. The theme of empowerment came through in relation to the cited affective outcomes. In their interviews, the teachers in the current study talked about feeling more confident and empowered to teach outdoors.

\section{Attitudinal change}

Whilst change was evidenced across the four areas of impact for the teachers, attitudinal change can be highlighted as a key driver to long term, sustainable change in the practice of teaching outdoors. Attitudinal change and the link with behavioural change (actual ongoing teaching practice) can be difficult to prove with the argument that teacher practices only partially correspond to their beliefs and attitudes (Mansour, 2013). However, all of the teachers reported longer term plans for each school and changes to classroom practice. In addition, all of the schools involved in the current project have continued their commitment to this work through their involvement in a three year coteaching project to further develop learning in the outdoors with their partner schools and with other class groups. Involvement in such a project is evidence of long term behavioural change. Nevertheless, future research is needed to further investigate and measure attitudinal change and the effects of improvements in teacher attitudes and actual teaching behaviour (van Aalderen-Smeets and Walma van der Molen, 2015).

\section{Conclusions}

The findings presented in this paper evidence a real proof of concept for the approach of using a coteaching model and a blended CPD approach to effectively improve and develop teaching and learning in the outdoors, across the elementary and (junior) high school transition phase. With reference to the research questions, teachers talked at length about how the project enhanced their skills for teaching and learning in the outdoors. They talked about learning how 
to use the equipment and teaching the children such skills. There was a focus on the benefits of autonomous planning of such skills-based teaching and longer term changes to their practice, in relation to using the outdoors more confidently.

The project reported in this paper shows real potential for the roll out of such practice across the transition stage and it would be interesting to 'test' this model on a larger scale. More specifically, it is recommended that future research considers the longer term benefits of such empowerment and autonomy for teachers teaching in the outdoors, in relation to the continued development of their teaching practice. A closer examination of the relationship between attitudinal change and behavioural practice, for both coteachers and students, is also merited as well as the measurement of potential environment-related benefits (connection to nature and wellbeing in particular). The final word in relation to the effectiveness of the model reported here belongs to those for whom it was designed:

Seeing the pupils, their enthusiasm, how they loved being outside, the pond, looking at creatures, it was amazing. I've never seen them so engaged and enthusiastic about something...it was really, really positive.

([junior] high school teacher)

\section{Funding}

This work was funded by the Primary Science Teaching Trust (PSTT).

\section{References}

Addis, J., Reid, F., McAlister, P., \& Shine, J. (2007). Primary Science: Beyond the Borders. Education in Science, 222, 10-11.

Ardoin, N.M., Bowers, A.W., Wynam Roth, N., \& Holthuis, N. (2018).

Environmental education and K-12 student outcomes: A review and analysis of research. The Journal of Environmental Education, 49(1), 1-17. 
Bandura, A. (1994). Self-efficacy. In V.S. Ramachaudran (Ed.), Encyclopaedia of human behaviour (pp. 71-81). New York: Academic Press.

Charmaz, K. (2000). Grounded Theory, Objectivist and Constructivist Methods. In N.K. Denzin \& Y.S. Lincoln (Eds.), Handbook of Qualitative Research (pp. 509-535). London: Sage Publications Limited.

Chi, M.T.H. (1997). Quantifying Qualitative Analyses of Verbal Data: A Practical Guide. The Journal of Learning Sciences, 6(3), 271-315.

Cohen, L., Mannion, L. \& Morrison, K. (2007). Research Methods in Education. London: Routledge.

Council for Curriculum Examinations and Assessment [CCEA] (2007). The Northern Ireland Curriculum Primary. Belfast, UK: CCEA.

Dillon, J. \& Dickie, I. (2012). Learning in the Natural Environment: Review of social and economic benefits and barriers. Natural England Commissioned Reports, Number 092.

Dillon, J., Rickinson, M., Teamey, K., Morris, M., Young Choi, M., Sanders, D., \& Benefield, P. (2006). The value of outdoor learning: evidence from research in the UK and elsewhere. School Science Review, 87(320), 107-111.

Gallagher, C. (2009). Designing a Curriculum for the 21st Century: A Case Study of Northern Ireland's Curriculum Review. Belfast, UK: Qualifications and Curriculum Authority.

Hanna, G. (1992, October). Jumping deadfall: Overcoming barriers to implementing outdoor and environmental education. Paper presented at the International Conference for the Association of Experiential Education, Alberta, Canada. Mansour, N. (2013). Consistencies and inconsistencies between science teachers' beliefs and practices. International Journal of Science Education, 35(7), 1230-1275. 
Kerr, K. (2010). "It Certainly Taught Us How to Change Our Minds on Teaching Science": Coteaching in Continuing Professional Development. In C. Murphy and K. Scantlebury (Eds.), Coteaching in International Contexts Research and Practice (pp. 151171). Dordrecht, The Netherlands: Springer.

Kerr, K. (2016). Science learning in the outdoors to support primary-secondary transition. School Science Review, 98(362), 27-32.

Martin, S. (2009). Learning to teach science. In K. Tobin and W.-M. Roth (Eds.), World of Science Education: North America (pp. 567-586). The Netherlands: Sense Publishers.

Murphy, C., \& Beggs, J. (2010). A Five-year Systematic Study of Coteaching Science in 120 Primary Schools: Coteaching in Continuing Professional Development. In C. Murphy and K. Scantlebury (Eds.), Coteaching in International Contexts Research and Practice (pp. 11-34). Dordrecht, The Netherlands: Springer.

Murphy, C., Bianchi, L., McCullagh, J., \& Kerr, K. (2013). Scaling up higher order thinking skills and personal capabilities in primary science: Theory-into-policy-into-practice. Thinking Skills and Creativity, 10, 173- 188.

Murphy, C., \& Scantlebury, K. (2010). Introduction to Coteaching: Coteaching in Continuing Professional Development. In C. Murphy and K. Scantlebury (Eds.), Coteaching in International Contexts Research and Practice (pp. 1-7). Dordrecht, The Netherlands: Springer.

Murphy, C., Scantlebury, K., \& Milne, C. (2015). Using Vygotsky’s zone of proximal development to propose and test an explanatory model for conceptualising coteaching in preservice science teacher education. Asia-Pacific Journal of Teacher Education, 43(4), 281295. 
Natural Connections Project (2016) Transforming outdoor learning in schools, Lessons from the Natural Connections Project. UK: University of Plymouth.

Nundy, S., Dillon, J., \& Dowd, P. (2009). Improving and encouraging teacher confidence in out-of-classroom learning: the impact of the Hampshire Trailblazer project on 3-13 curriculum practitioners. Education 3-13, 37(1), 61-73.

Rickinson, M., Dillon, J., Teamey, K., Morris, M., Young Choi, M., Sanders, D., \& Benefield, P. (2004). A review of research on outdoor learning. England: Field Studies Council.

Rickinson, M., Hunt, A., Rogers, J. \& Dillon, J. (2012). School Leader and Teacher Insights into Learning Outside the Classroom in Natural Environments. Natural England Commissioned Reports, Number 097.

Rodrigues, S., Marks, A., \& Steel, P. (2003). Developing science and ICT pedagogical content knowledge: A model of continuing professional development. Innovations in Education and Teaching International, 40(4), 386-394.

Roth,W.-M. (2007). Toward solidarity as the ground for changing science education. Cultural Studies of Science Education, 2, 721-783.

Siry, C., \& Martin, S.N. (2010). Coteaching in Science Education Courses: Transforming Teacher Preparation Through Shared Responsibility. In C. Murphy and K. Scantlebury (Eds.), Coteaching in International Contexts Research and Practice (pp. 57-78). Dordrecht, The Netherlands: Springer.

Stern, M.J., Powell, R.B., \& Hill, D. (2014). Environmental education program evaluation in the new millennium: What do we measure and what have we learned? Environmental Education Research, 20(5), 581-611.

The Education and Training Inspectorate (2015) An evaluation of the implementation of The World Around Us in primary schools. Belfast, UK: ETI 
Tobin, K., \& Roth,W.-M. (2006). Teaching to learn: Perspectives from the field. Rotterdam, The Netherlands: SensePublishers.

University of Southern California (2013). Reach, the publication for education research, 8. Los Angeles, CA: University of Southern California, Rossier School of Education.

van Aalderen-Smeets, S.I., \& Walma van der Molen, J.H. (2015). Improving Primary Teachers' Attitudes Toward Science by Attitude-Focused Professional Development. Journal of Research in Science Teaching, 52(5), 710-734.

Waite, S. (2011) Teaching and learning outside the classroom: personal values, alternative pedagogies and standards. Education 3-13, 39(1), 65-82.

Waite, S. (2013). Making a difference: learning on a grand scale. In S. Waite (Ed.), Children Learning Outside the Classroom (pp. 201-212). London: SAGE.

Waite, S., Passy, R., Gilchrist, M., Hunt, A. \& Blackwell, I. (2016). Natural Connections Demonstration Project, 2012-2016: Final Report. Natural England Commissioned Reports, Number215. 